\title{
IN-VITRO INDUCTION OF MEIOTIC DIVISION IN FOLLICLE-ENCLOSED RAT OOCYTES BY LH, CYCLIC AMP AND PROSTAGLANDIN $E_{2}$
}

\author{
A. TSAFRIRI, H. R. LINDNER, U. ZOR AND S. A. LAMPRECHT
}

Department of Biodynamics, The Weizmann Institute of Science, Rehovot, Israel

(Received 17th August 1971, accepted 2nd December 1971)

Summary. Isolated Graafian follicles cultured intact were used as a test-system for the meiosis-inducing action of hormonal preparations and for analysing the mediation of this hormone effect.

When enlarged follicles were explanted from rats on the day of prooestrus before 14.00 hours, i.e. before the preovulatory LH-surge, the oocytes remained in the dictyate state of meiosis throughout an 18-hr culture period. Completion of the first meiotic division could be induced by addition of $\mathrm{LH}$ or prostaglandin $\mathrm{E}_{2}$ to the culture medium, or by microinjection of dibutyryl cyclic AMP into the antrum of the cultured follicle. Addition of HCG or FsH to the culture medium was also effective, though possibly due to LH-like activity present in these preparations. Prostaglandin $\mathrm{F}_{2 \alpha}$, at $2 \cdot 8 \times 10^{-5} \mathrm{M}$, was only partly effective; prolactin, progesterone, $20 \alpha$-dihydroprogesterone, oestradiol-17 $\beta$, linolenic acid and adenosine-5'-monophosphate were completely ineffective. The maturation-inducing action of LH was not blocked by cyanoketone, an inhibitor of steroid synthesis.

Addition of $\mathrm{LH}$ to the culture medium stimulated the formation of cyclic AMP by the isolated follicles. Exogenous cyclic AMP enhanced protein kinase activity in the supernatant fraction of follicular homogenates.

It is proposed that the action of $\mathbf{L H}$ on oocyte maturation involves the mediation of the adenyl cyclase/cyclic AMP system and possibly of the prostaglandins. An action of steroids could not thus far be implicated. The experimental model described permits study of the mechanism of the meiosis-inducing action of $\mathrm{LH}$ under controlled conditions in vitro.

\section{INTRODUGTION}

Oocytes of many mammalian species, irrespective of their stage of development, will mature in hormone-free media in vitro if artificially released from their follicles (Pincus \& Enzmann, 1935; reviewed by Schuetz, 1969). Although of potential practical utility (Edwards, 1965; Edwards, Bavister \& Steptoe, 1969), this model can hardly represent the physiological events, since ovum maturation in vivo is clearly dependent on the release of hypophysial gonadotrophin(s) and precedes the rupture of the follicular wall. 
It is not clear which cellular component of the follicle is the primary target of the maturation-triggering action of gonadotrophin, nor what biochemical mechanism underlies this action. In some lower forms, e.g. in echinoderms and amphibia, an extraovarian hormone (radial nerve factor and hypophysial gonadotrophin, respectively) acts on the follicular cells, and these respond by releasing a substance that stimulates the oocyte to resume meiosis: 1-methyladenine in the starfish (Kanatani, 1969) and possibly progesterone in Rana pipiens (Smith \& Ecker, 1970). Moreover, maturation of mammalian oocytes in vitro seems to be favoured by retention of the corona and cumulus cells (Robertson \& Baker, 1969; Cross \& Brinster, 1970), again suggesting an influence of these follicular cells on the behaviour of the oocyte.

The stimulatory action of $\mathrm{LH}$ on ovarian steroidogenesis appears to be mediated by cyclic adenosine $3^{\prime}, 5^{\prime}$-monophosphate (cAMP) and is also mimicked by prostaglandins (Robison, Butcher \& Sutherland, 1968; Marsh, 1970; Lamprecht, Zor, Tsafriri \& Lindner, 1971). There is no information on whether the adenyl cyclase-cAMP system or the prostaglandins are also implicated in the mechanism by which gonadotrophins effect ovum maturation.

We therefore studied the effect of $\mathrm{LH}$, and of substances known to mimic some of its actions, on the resumption of the meiotic process by rat oocytes cultured while maintaining their normal relationship to the follicular apparatus.

\section{MATERIALS AND METHODS}

\section{Animals}

Three-month-old Wistar-derived rats of the Biodynamics colony were used, that had shown at least two normal 4-day cycles, as determined by daily vaginal smears, immediately before the start of the experiment. The animals were housed in air-conditioned quarters illuminated between 05.00 and 19.00 hours. They were offered Purina Lab chow (Ralston Purina Co.) and water without restriction.

\section{Culture of follicle-enclosed oocytes}

Animals were killed by cervical dislocation either between 08.00 and 12.30 hours or between 19.00 and 20.00 hours on the day of pro-oestrus. The ovaries were collected at once and placed in Petri dishes containing Eagle's medium. Large follicles (about $1 \mathrm{~mm}$ in diameter) protruding from the surface of the ovaries were excised under a dissecting microscope (five- to tenfold magnification), using iris forceps and scissors. The follicles from each pair of ovaries (ten to fourteen) were placed on the stainless steel grid of a Falcon organ culture dish $(60 \times 15 \mathrm{~mm}$ diameter, Pl. 1, Fig. 1a) containing in its central compartment the medium, with or without addition of a hormone or other substance to be tested (see below), and in its outer compartment a water-soaked paper ring. The culture dishes were transferred into an incubator maintained at $37.5 \pm$ $0.5^{\circ} \mathrm{C}$ and flushed continuously with a mixture of $\mathrm{O}_{2}(66 \%)$ and $\mathrm{N}_{2}(34 \%)$ saturated with water.

Eagle's medium (Gibco) supplemented with $20 \%$ fetal calf serum (Gibco) was routinely used. In one experimental series, serum from rats bled on the 
morning of pro-oestrus was substituted for the fetal calf serum. The medium was adjusted to $\mathrm{pH} 7 \cdot 3$ with $2.383 \mathrm{~g} /$ litre HEPES $\left(\mathcal{N}-2\right.$ hydroxyethylpiperazine- $\mathcal{N}^{\prime}$ 2 -ethanesulphonic acid, Calbiochem), $0.5 \mathrm{ml} /$ litre of a $7.5 \%$ solution of sodium bicarbonate and an appropriate amount of $1 \mathrm{~N}-\mathrm{NaOH}$. The buffered medium was sterilized by filtration through a cellulose acetate membrane of $0 \cdot 22-\mu \mathrm{m}$ pore size (Millipore Corp.). Unless indicated in the text, the osmolality of this medium ( 280 mosmol) was reduced to 210 mosmol by addition of doubledistilled sterile water. Penicillin G (Assia, 100 units $/ \mathrm{ml}$ ), dihydrostreptomycin (Assia, $100 \mu \mathrm{g} / \mathrm{ml}$ ) and fungizone (Squibb, 2.5 $\mu \mathrm{g} / \mathrm{ml}$ ) were added to the medium. All additions of substances to be tested were made in a volume of $5 \mu \mathrm{l} / \mathrm{ml} \mathrm{medium}$. Steroid hormones and prostaglandins were first dissolved in absolute ethanol and diluted with water; the final concentration of ethanol in the medium never exceeded $1 \%$. Insulin (Calbiochem; bovine recrystallized, B grade) was dissolved in a minimal volume of $0.01 \mathrm{~N}-\mathrm{HCl}$ and added to the medium at a concentration of $5 \mu \mathrm{g} / \mathrm{ml}$, unless otherwise stated. The other hormone preparations used were LH (NIH-LH-s15), FSH (NIH-FSH-s8), HCG (Organon), progesterone (Ikapharm), oestradiol-17 $\beta$ (Organon) and 20 $\alpha-$ dihydroprogesterone (Ikapharm). Prostaglandins were the product of Upjohn Company (Kalamazoo, Michigan) and cyclic AMP and its dibutyryl derivative of Boehringer and Söhne (Mannheim). In control incubations, an equal volume of the corresponding vehicle was added to the incubation medium.

After 15 to $18 \mathrm{hr}$ incubation, the walls of the follicles were incised and their contents aspired with a micropipette and transferred to a depression slide. The ova were then picked up under a stereomicroscope and examined by Nomarski interference contrast microscopy. Ova showing no germinal vesicles and nucleolus were then treated according to the method of Tarkowski (1966) to render the chromosomes visible and examined under phase-contrast with an oil immersion lens.

\section{Microinjection into the follicular antrum in vitro}

Isolated follicles mounted on the steel grid of a Falcon organ culture dish were injected with various test substances in a volume of approximately 0.35 $\mu \mathrm{l} /$ follicle, using a microsyringe (Hamilton Company, Inc.) with a removable needle hub. A glass needle of fine bore (approximately $50 \mu \mathrm{m}$ outer diameter) was prepared with the aid of a pipette drawer (E. Leitz, G.m.b.H., Wetzlar) and fitted to the syringe with a Teflon adaptor. A small amount of follicular fluid usually escaped from the puncture hole on withdrawal of the needle so that a small portion of the injected drug was probably lost. Adenosine-5'-monophosphate used in control injections was the product of Sigma (derived from equine muscle).

\section{Production of cAMP}

Follicles were incubated for $3 \mathrm{hr}$ with $\left[{ }^{3} \mathrm{H}\right]$ adenine $(25 \mu \mathrm{Ci} / 2 \mathrm{ml} ; 2.02 \mathrm{Ci} /$ $\mathrm{mm}$ ) at $37^{\circ} \mathrm{C}$ to label the endogenous ATP pool. The tissue was washed free of radioactive adenine and re-incubated for $20 \mathrm{~min}$ in the presence of theophylline with added LH or prostaglandin, or in a control medium. The ${ }^{3} \mathrm{H}$-labelled cAMP so formed was purified and determined as described by Kaneko, Zor \& 
Field (1970). Alternatively, the level of cyclic AMP in the tissue was determined by the competitive protein-binding assay of Gilman (1970), following incubation of the follicles with or without added LH or prostaglandin $E_{2}$ for $15 \mathrm{~min}$.

\section{Activation of protein kinase}

The 27,000 g supernatant of a homogenate of isolated Graafian follicles was incubated for $10 \mathrm{~min}$ with or without the addition of cAMP $\left(5 \times 10^{-5} \mathrm{M}\right)$ in the presence of histone and ${ }^{32} \mathrm{P}-\gamma$-labelled ATP, and net incorporation of ${ }^{32} \mathrm{P}$ into histone was determined by the method of Miyamoto, Kuo \& Greengard (1969) as modified by Gilman (1970).

\section{RESULTS}

Action of gonadotrophins on the follicle in vitro

Behaviour of explanted follicles in hormone-free media. The fate of the oocytes in follicles cultured intact depended on the time of their collection. Those explanted on the day of pro-oestrus before 13.00 hours, that is, before the critical period (Everett, 1961; Tsafriri \& Kraicer, 1972) and the onset of the preovulatory LHsurge in our colony (Ayalon, Tsafriri, Lindner, Cordova \& Harell, 1972), retained their germinal vesicle, with few exceptions (about $4 \%$ ), and did not show any signs of maturation when cultured in the absence of LH (Text-fig. 1). By contrast, $87 \%$ of oocytes in follicles collected during the evening on the day of pro-oestrus (19.00 to 20.00 hours) and explanted into hormone-free media had completed meiosis when examined after $12 \mathrm{hr}$ culture. Hence, follicles explanted during the morning of pro-oestrus were used in all subsequent experiments designed to detect the meiosis-inducing action of LH or other agents.

The criteria for resumption of meiosis by the cultured oocytes were (i) dissolution of the germinal vesicle, and particularly the disappearance of its nucleolus; (ii) formation of a perivitelline space; (iii) extrusion of the first polar body-only rarely demonstrable because of its instability in the rat; and (iv) condensation of the chromosomes, as revealed by cytological examination of stained air-dried preparations, and replacement of the tetrads by dyads. (Many of the oocytes collected after 19.00 hours-about $75 \%$-had already lost their germinal vesicle and nucleolus in vivo.)

When using media considered to be isotonic (280 mosmol), many of the oocytes collected on the morning of pro-oestrus and not exposed to $\mathrm{LH}$ in vitro exhibited cytoplasmic shrinkage, with retraction of the egg membrane from the zona pellucida, or signs of degeneration (Text-fig. 1). These effects on the control oocytes could be avoided by lowering the osmolality of the medium to 210 mosmol, and this procedure was routinely adopted. However, it was later found that oocytes in follicles cultured in LH-enriched media (see below) showed no adverse effects when the tonicity of the medium was increased to 280 mosmol (Text-fig. 1).

Induction of meiosis in vitro by $L H$. Oocytes in follicles explanted during the morning of pro-oestrus could be induced to resume meiosis in culture by the addition of LH to the medium. 

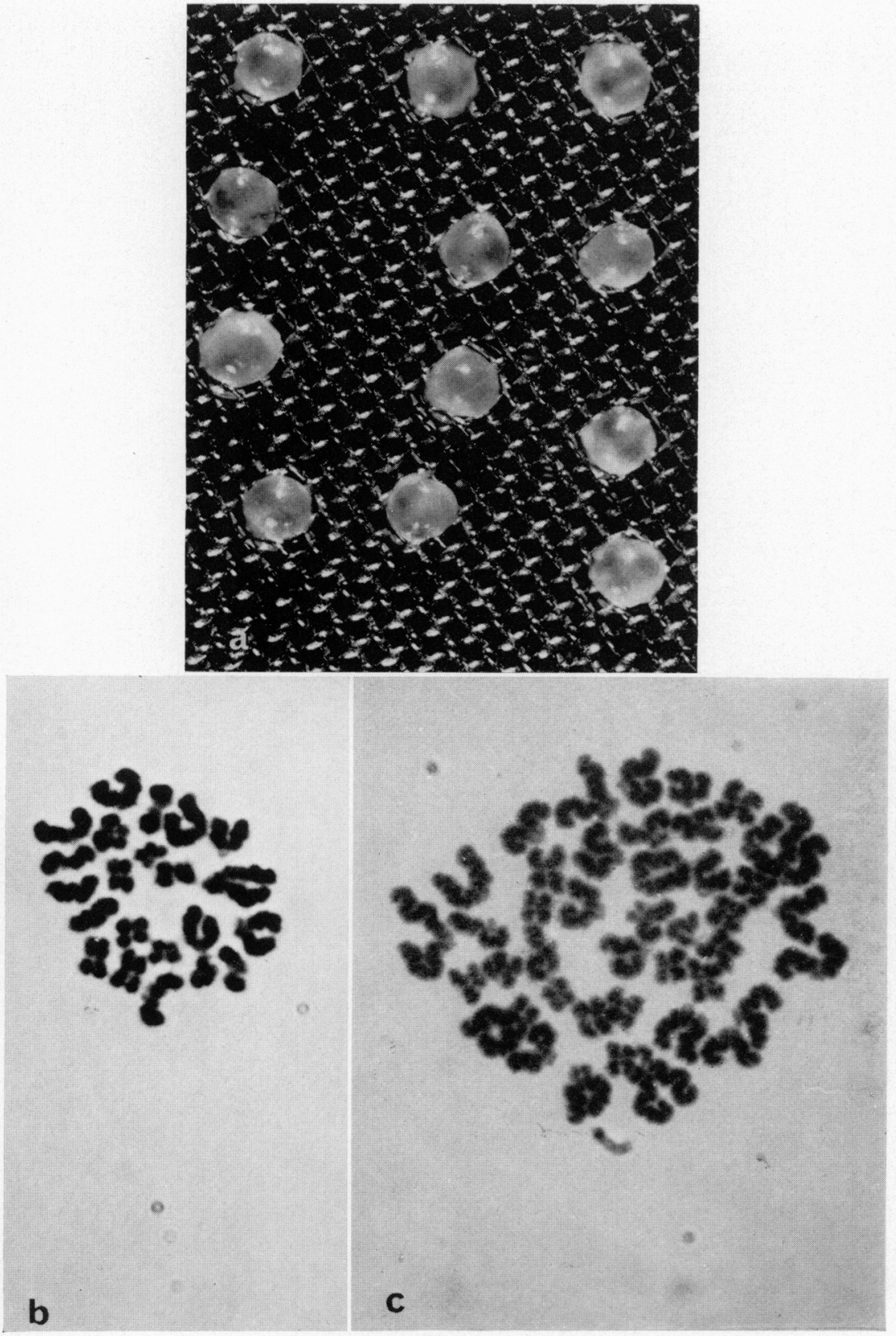

Fig. 1. Culture of intact follicles. (a) Explanted follicles on stainless steel grid (mean pore diameter, $0.3 \mathrm{~mm}$ ). (b) and (c) Chromosomes of oocytes from follicles cultured in medium containing LH ( $5 \mu \mathrm{g} / \mathrm{ml}$ ) : (b) normal second metaphase (2l dyads); (c) abnormal number of dyads (42) due to failure to form first polar body.

(Facing p. 42) 
Concentrations in the medium of $0 \cdot 1 \mu \mathrm{g} \mathrm{LH} / \mathrm{ml}$ or less had no significant effect on the oocytes. Levels between 0.5 and $1.0 \mu \mathrm{g} \mathrm{LH} / \mathrm{ml}$ were sufficient to bring about maturation changes in $82 \%(55 / 67)$ of the oocytes, including dissolution of the germinal vesicle, appearance of tetrads and dissociation of the bivalets, but in the majority of oocytes $(61 \%)$, the process was arrested at this stage and chromosome preparations revealed the presence of 42 dyads (Pl. 1, Fig. 1c), i.e. a tetraploid complement of chromatids. This indicated a disturbance in the separation of the anaphase chromosomes during the first meiotic division and

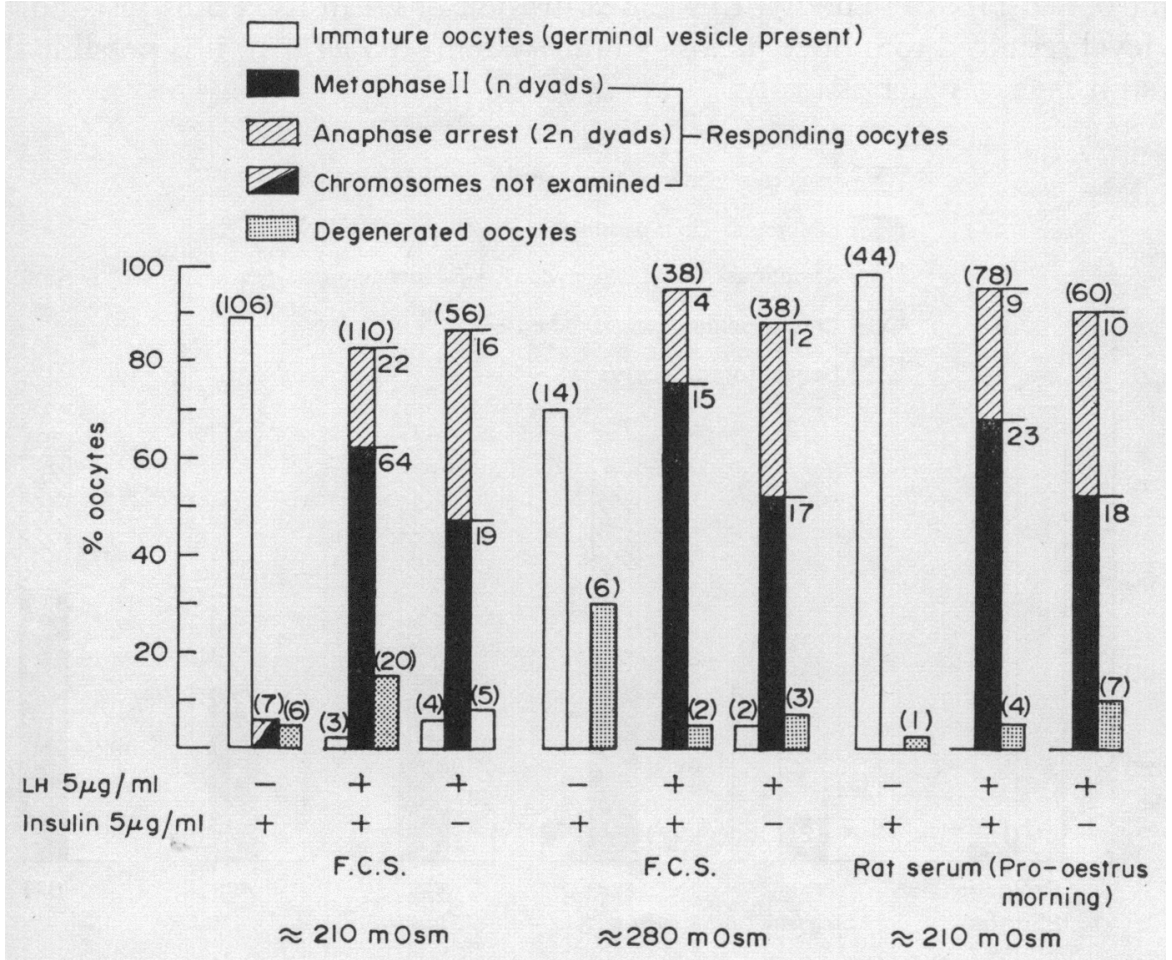

TEXT-FIG. 1. Effect of culture conditions on LH-induced ovum maturation. The number of oocytes recovered after culture is indicated in parentheses on top of columns. The number of chromosome counts carried out is indicated at side of columns. F.C.S. = fetal calf serum.

failure to extrude the first polar body. Better results ( 84 to $95 \%$ responding oocytes) were obtained with 5 to $10 \mu \mathrm{g} \mathrm{LH} / \mathrm{ml}$ in the medium and a concentration of $5 \mu \mathrm{g} / \mathrm{ml}$ was routinely adopted (Text-fig. 1). Even under these conditions, some of the responding oocytes retained 42 chromosomes. Addition of insulin $(5 \mu \mathrm{g} / \mathrm{ml})$ to the culture medium slightly but consistently reduced the incidence of this abnormality and was routinely adopted. Thus, in the presence of LH (5 $\mu \mathrm{g} / \mathrm{ml})$ and insulin $(5 \mu \mathrm{g} / \mathrm{ml})$ the majority of the responding oocytes $(72$ to $79 \%$, Text-fig. 1) were found at the end of the culture period to be in second metaphase (containing twenty-one dyads, Pl. 1, Fig. 1b), and morphologically resembled normal fertilizable oocytes. 
Substitution of rat serum (see 'Materials and Methods') for fetal calf serum in the medium did not significantly improve the results (Text-fig. 1).

Other gonadotrophic preparations. Of other preparations tested, HGG (5 to 10 i.u./ml medium) and FSH (10 to $20 \mu \mathrm{g} / \mathrm{ml}$ ) were also effective in inducing resumption of meiosis in the cultured oocytes, but ovine prolactin ( 1 to 25 $\mu \mathrm{g} / \mathrm{ml}$ ) was inactive (Text-fig. 2). The FSH preparation used was stated to contain a small amount of LH-like activity (equivalent to $15 \mu \mathrm{g}$ NIH-LH-s $15 / \mathrm{mg}$ by an ascorbic acid depletion assay). The minimal effective concentration of FsH in the medium $(10 \mu \mathrm{g} / \mathrm{ml})$ was thus equivalent to $0 \cdot 15 \mu \mathrm{g} / \mathrm{ml}$ of LH-like activity in terms of NIH-LH-S15. Though this concentration of LH in itself falls just short of the level required to induce meiosis in our system $(0.5 \mu \mathrm{g} / \mathrm{ml})$, it is possible that FSH and LH act synergistically.

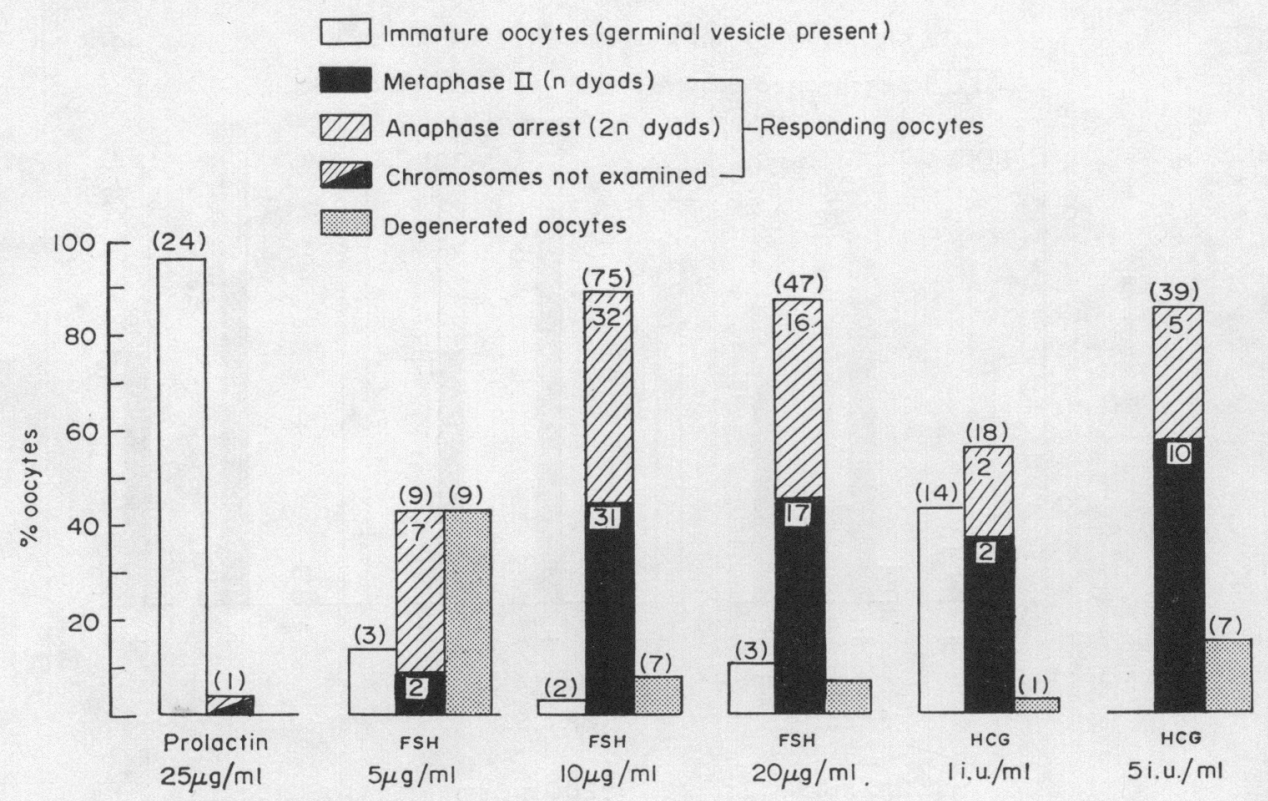

TEXT-FIG. 2. Hormonal induction of ovum maturation in vitro. The number of oocytes recovered is indicated in parentheses on top of columns. The number of chromosome counts carried out is indicated within the columns. For description of hormonal preparations used and of experimental conditions, see 'Materials and Methods' section.

Rôle of ovarian steroids. Progesterone $\left(1.6 \times 10^{-5}\right.$ to $\left.1.6 \times 10^{-4} \mathrm{M}\right), 20 \alpha$-dihydroprogesterone $\left(1.6 \times 10^{-5}\right.$ to $\left.1.6 \times 10^{-4} \mathrm{M}\right)$ and oestradiol-17 $\beta\left(10^{-9}\right.$ to $\left.10^{-15} \mathrm{M}\right)$ were all completely ineffective in triggering meiotic changes. Furthermore, in a preliminary experiment, the addition of $2 \alpha$-cyano- $4,4,17 \alpha$-trimethyl-androst-5en-17 $\beta$-ol-3-one (cyanoketone; $3 \times 10^{-5} \mathrm{M}$ ) to the medium did not prevent the in-vitro initiation of oocyte maturation by LH: $79 \%(30 / 38)$ of the explanted oocytes lost their germinal vesicle, though an unusually high percentage of these $(68 \%)$ failed to extrude the first polar body, as indicated by the retention of 42 chromosomes. Neither oestradiol- $17 \beta\left(10^{-9}\right.$ to $\left.10^{-15} \mathrm{M}\right)$ nor progesterone $\left(3 \times 10^{-6} \mathrm{M}\right)$ inhibited the meiosis-inducing action of $\mathbf{L H}$. 
Rôle of cyclic AMP. Luteinizing hormone markedly stimulated production of cyclic AMP by the isolated rat follicle, whether this was assessed by the rate of incorporation of $\left[{ }^{3} \mathrm{H}\right]$ adenine into cyclic AMP (Text-fig. 3), or by determination of the cAMP level in the tissue according to Gilman (1970). In the latter

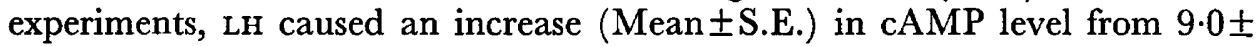
0.84 to $216.0 \pm 7.6 \mathrm{pmol} / \mathrm{mg}$ tissue during $20 \mathrm{~min}$ incubation. Cyclic AMP, in turn, enhanced protein kinase activity in the supernatant fraction of homogenates from such follicles: ${ }^{32} \mathrm{P}$-incorporation into histone increased from a

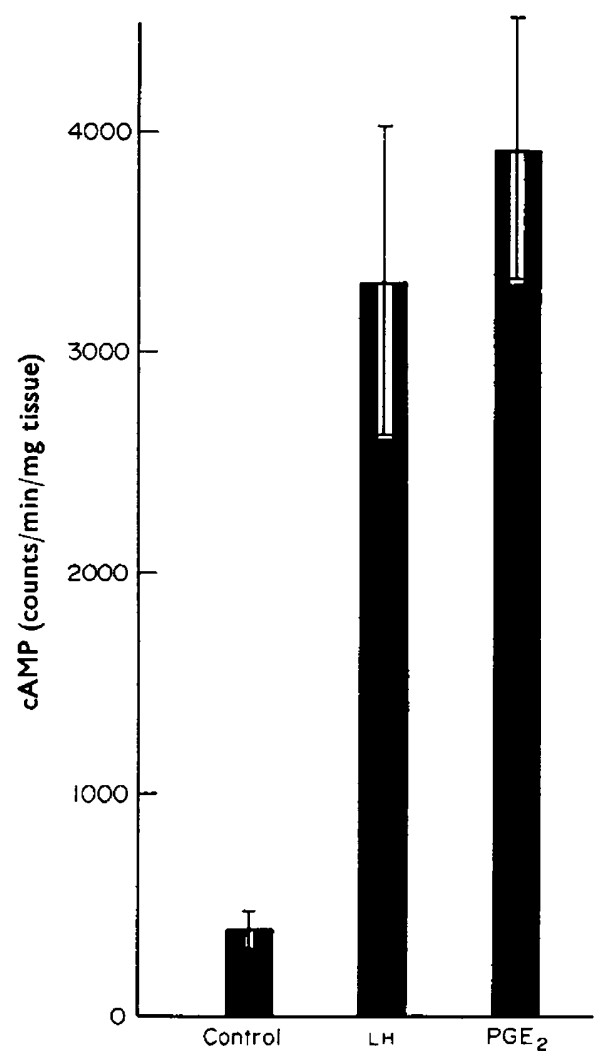

TEXT-FIG. 3. Effect of $\mathrm{LH}$ and prostaglandin $\mathrm{E}_{2}$ on synthesis of cyclic AMP by isolated Graafian follicles. Isolated Graafian follicles were incubated for $3 \mathrm{hr}$ in a medium containing $\left[{ }^{3} \mathrm{H}\right]$ adenine, washed and re-incubated for $20 \mathrm{~min}$ in a medium containing theophylline and the substance to be tested; $\left[{ }^{3} \mathrm{H}\right]$ cyclic AMP formation was determined as described in the 'Materials and Methods' section.

control level of 8200 counts $/ \mathrm{min} / \mathrm{mg}$ tissue to 29,700 counts $/ \mathrm{min} / \mathrm{mg}$ in the presence of cAMP $\left(5 \times 10^{-5} \mathrm{M}\right)$. Nevertheless, our attempts to induce ovum maturation in vitro by adding cAMP $\left(2.9 \times 10^{-4}\right.$ to $\left.1.4 \times 10^{-3} \mathrm{M}\right)$ or its dibutyryl derivative (DBC, $2 \times 10^{-5}$ to $\left.10^{-3} \mathrm{M}\right)$ with or without theophylline $\left(5 \times 10^{-3} \mathrm{M}\right)$ to the medium yielded negative results.

Since the failure of cAMP to elicit a meiotic response when added to the culture medium might be attributable to a permeability barrier, we injected the 
dibutyryl derivative of this nucleotide, in another series of experiments, directly into the follicular antrum. The results are shown in Text-fig. 4. When

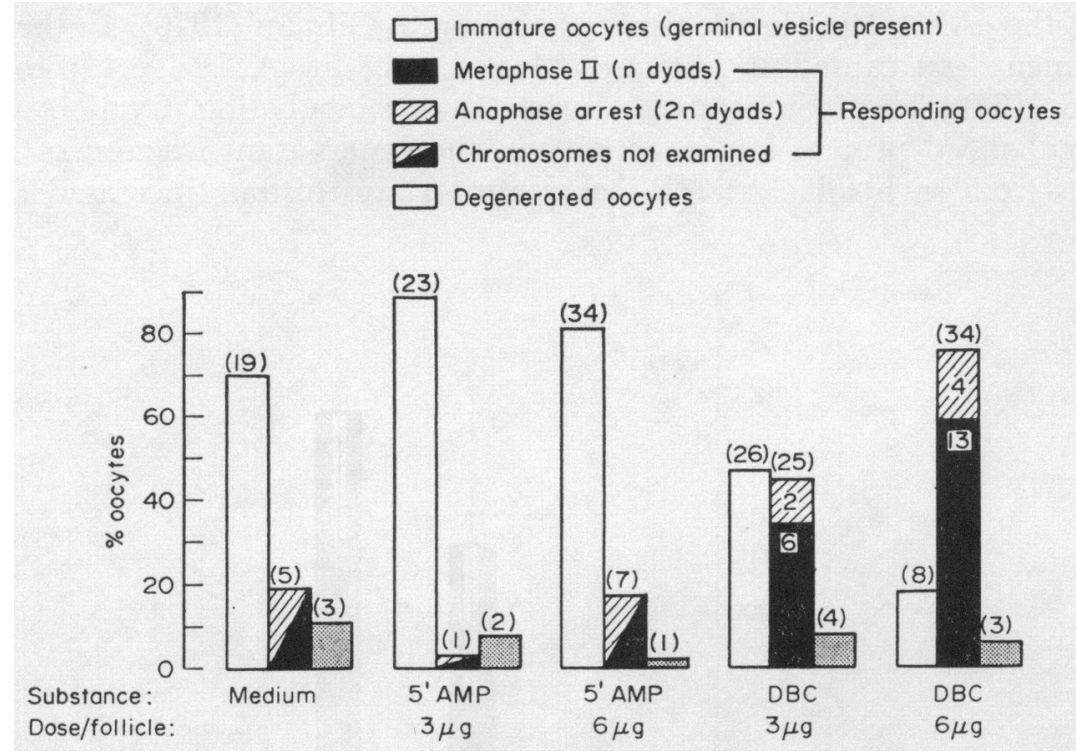

TEXT-Frg. 4. Induction of ovum maturation in vitro by injection of dibutyryl cyclic AMP into the follicular antrum. DBC, dibutyryl cyclic AMP. (The numbers appearing on the columns are explained in the legend to Text-fig. 2.)

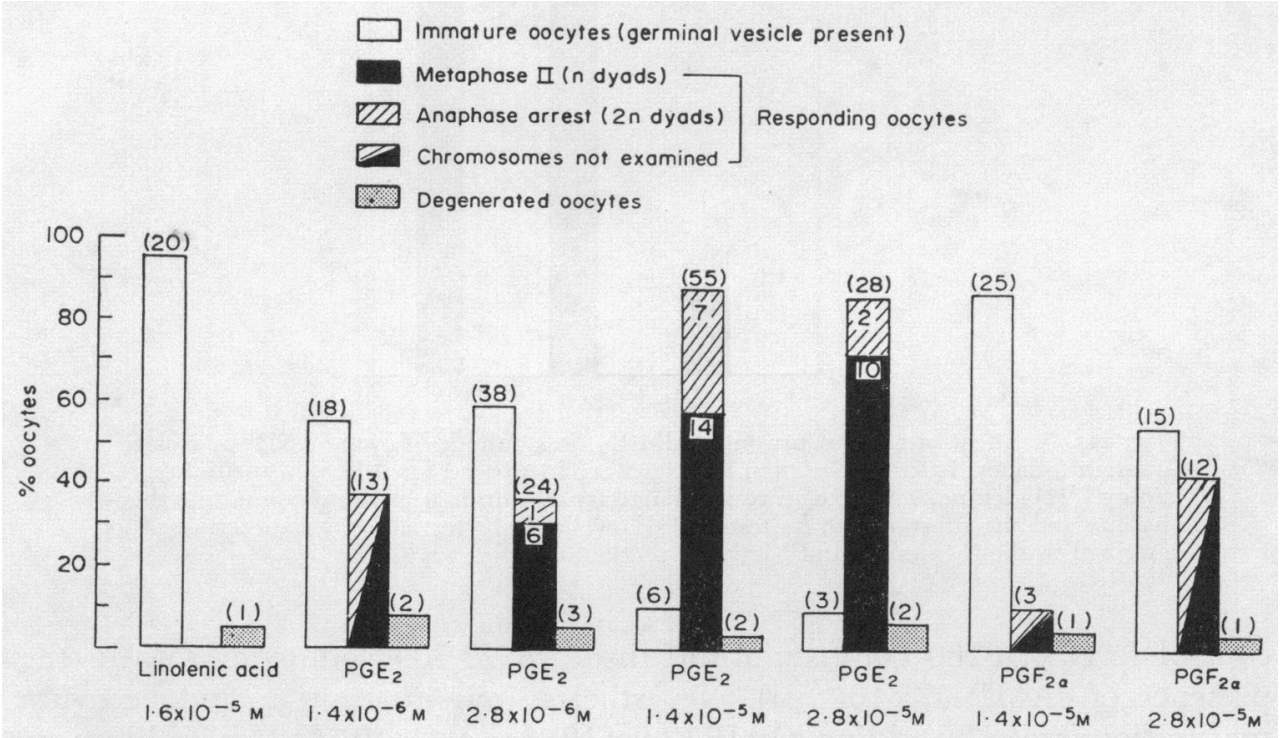

TEXT-FIG. 5. Induction of ovum maturation in vitro by prostaglandins. PG, prostaglandin. (The numbers appearing on the columns are explained in the legend to Text-fig. 2.)

DBC was applied at the dose level of $6 \mu \mathrm{g}$ per follicle (equivalent to $4 \mu \mathrm{g}$ of the free nucleotide), $76 \%$ of the oocytes resumed meiosis. Control injections of an 
equal volume of the medium or of adenosine-5'-monophosphate (3 to $6 \mu \mathrm{g}$ ) caused only 3 to $19 \%$ of the oocytes to lose their germinal vesicle.

Induction of meiosis by prostaglandins. Prostaglandin $\mathrm{E}_{2}$ mimicked the action of LH in enhancing cyclic AMP formation in the isolated rat ovarian follicles (Text-fig. 3). This finding was corroborated by determining the level of cAMP in the follicles using the method of Gilman (1970). Furthermore, addition of prostaglandin $\mathrm{E}_{2}$ to the medium $\left(1.4 \times 10^{-6}\right.$ to $\left.2.8 \times 10^{-5} \mathrm{M}\right)$ induced completion of the first maturation division in cultured follicles. The higher dose levels $\left(1.4\right.$ to $\left.2.8 \times 10^{-5} \mathrm{M}\right)$ were as effective as the optimal dose of LH (Text-fig. 5). Prostaglandin $\mathrm{F}_{2 \alpha}$ was ineffective at $1.4 \times 10^{-5} \mathrm{M}$ and only partly effective even at $2.8 \times 10^{-5} \mathrm{M}$, and linolenic acid (serving as a control) was completely ineffective. Only three rats were used at each dose-level of prostaglandin $F_{2 \alpha}$, and furthermore, a still higher dose of this compound might well have induced ovum maturation. Nevertheless, it appears that prostaglandin $\mathrm{F}_{2 \alpha}$ is less effective in this respect than its $E_{2}$ congener.

\section{Behaviour of theca and granulosa cells in cultured follicles}

Whether oocyte maturation was induced by $\mathrm{LH}_{\mathrm{H}}$ or prostaglandin $\mathrm{E}_{2}$, none of the follicles ruptured during the culture period, even if this was prolonged to $48 \mathrm{hr}$, and none of the oocytes was spontaneously released. On the other hand, the follicles showed signs of luteinization when culture was continued for $48 \mathrm{hr}$ in the presence of $\mathbf{L H}$, after removal of the oocyte.

\section{DISCUSSION}

The work described establishes that follicle-enclosed rat oocytes explanted before the preovulatory LH surge into a hormone-free medium will remain in the dictyate state, but can be induced to resume meiosis by adding LH to the medium. This finding makes it possible, for the first time, to explore the mechanism of the meiosis-inducing action of $L_{H}$ in an in-vitro system. A previous attempt (Foote \& Thibault, 1969) to induce maturation of mammalian oocytes (cow and sow) in intact follicles in vitro by addition of $\mathrm{LH}$ or $\mathrm{FSH}$, or by coculture with a pituitary fragment, failed. The discrepancy may be due to the developmental stage of the follicles explanted, differences in culture conditions, or to interspecific differences.

Ovum maturation could also be induced, in our experiments, by addition of HCG or FSH to the culture medium. Both preparations contained LH-like activity, but the amount of LH present in the meiosis-inducing dose of FSH was probably too low $(0.15 \mu \mathrm{g} / \mathrm{ml}$ medium) to account, in itself, for the effect observed. Harrington, Bex, Elton \& Roach (1970) induced ovulation in chlorpromazineblocked rats with chymotrypsin-treated FSH, almost devoid of detectable LH-like activity, but a participation of the animals' pituitaries in the response cannot entirely be ruled out in their experiments. Definitive proof of an independent action of FSH on oocyte maturation in vitro would require the demonstration of its efficacy in the presence of anti-LH antibodies, or the use of a more highly purified FSH preparation.

The majority of the oocytes matured under the culture conditions described, 
in the presence of an adequate concentration of $\mathrm{LH}$, reached a stage morphologically indistinguishable from the second metaphase of meiosis. The ultimate test for the normality of such secondary oocytes would be the demonstration of their ability to be fertilized and subsequently to develop normally. This has not yet been attempted.

A proportion of the follicle-enclosed oocytes matured in vitro showed a disturbance in anaphase separation of the chromosomes during the first meiotic division, resulting in the retention of a tetraploid chromatid complement. The incidence of this abnormality was increased by suboptimal gonadotrophin concentration in the medium, and reduced by inclusion of insulin in the medium. The reason for this insulin effect is not clear, particularly since follicle-enclosed oocytes explanted after having been exposed to endogenous LII showed no deviation from normal chromosome number even when cultured in insulin-free media. Perhaps insulin assists the initial interaction of LH with its target cell.

Amphibian eggs can be induced to resume meiosis by treatment with progesterone (Smith \& Ecker, 1970). Rondell (1970), studying porcine ovaries, proposed that LH induces changes in vitro in the distensibility of the follicular wall conducive to ovulation, and that these changes are mediated by progesterone. Moreover, Lipner \& Greep (1971) found that ovulation could be prevented in immature PMSG- and LH-treated rats by administration of inhibitors of steroidogenesis, including cyanoketone, within 4 to $6 \mathrm{hr}$ of the LH injection. By contrast, we failed to induce maturation changes in cultured follicles by addition of progesterone, $20 \alpha$-dihydroprogesterone or oestradiol-17 $\beta$ to the medium; nor was the action of LH on the cultured follicles blocked by the addition of cyanoketone to the medium. None of the steroids tested inhibited the action of LH. We have not yet examined, however, whether exogenous progestagens or cyanoketone actually penetrate the follicle.

Cyclic AMP has been implicated in the steroidogenic action of LH in the ovary (Savard, Marsh \& Rice, 1965; Channing, 1970). Nevertheless, our attempts to induce ovum maturation in vitro by adding cAMP or its dibutyryl derivative to the culture medium were unsuccessful. Direct injection of dibutyryl cAMP into the follicular antrum, however, brought about completion of the first meiotic division, suggesting that entrance of exogenous nucleotide into the follicle may be impeded by the thecal layer(s). These findings, together with the demonstration that LH enhances adenyl cyclase activity in isolated follicles (Text-fig. 3), support the hypothesis that the action of LH on ovum maturation is mediated by cyclic AMP. Furthermore, our experiments showed that addition of exogenous cAMP to a supernatant fraction from homogenized follicles markedly stimulated histone phosphorylation. It is widely held that many of the biological actions of cAMP are mediated by an activation of protein kinase(s) (Gill \& Garren, 1971; Reimann, Brostrom, Corbin, King \& Krebs, 1971 ), though it is too early to say whether protein kinases have any rôle in the regulation of ovum maturation.

Endogenous cAMP production by the follicle was also stimulated by prostaglandin $\mathrm{E}_{2}$, at least to the same extent as by LH. This agent, too, proved capable of inducing ovum maturation in vitro with high efficiency. The phenomenon exhibited some degree of specificity in that prostaglandin $F_{2 \alpha}$ was much less 
effective per unit weight, and linolenic acid proved inert. Kuehl, Humes, Tarnoff \& Ham (1970) proposed that the prostaglandins constitute an essential link in the stimulatory action of LH on cAMP formation and steroidogenesis, but this view has been disputed (Marsh, 1971 ; Zor, Lamprecht, Kaneko, Schneider, McCann, Field, Tsafriri \& Lindner, 1972). Further work is clearly required to clarify whether the observed effect of prostaglandin $E_{2}$ on the follicle is merely a pharmacological one, or whether the prostaglandins have indeed a physiological rôle in the mediation of $\mathbf{L H}$ action on the oocyte. The assay of endogenous prostaglandins in the ovary, and the use of inhibitors of prostaglandin synthesis or of prostaglandin action, in conjunction with $\mathrm{LH}$, should be informative in this respect.

The fact that free oocytes complete meiosis spontaneously when cultured may suggest that the LH removes an inhibitory influence exerted on the oocyte by the granulosa cells (Pincus \& Enzmann, 1935; Foote \& Thibault, 1969); alternatively, the hormone may induce the elaboration and release of a positive signal by the follicular cells, which may be a prostaglandin and/or cyclic AMP, or even a steroid. Finally, LH may merely alter the permeability of the follicular wall to respiratory gases or to a critical metabolite. While many of these issues remain unresolved, the experimental model described seems to offer a chance to analyse in greater detail the rôle of the different cellular and subcellular components of the follicular apparatus in the action of LH on ovum maturation.

\section{ACKNOWLEDGMENTS}

The LH, FSH and prolactin preparations used were kindly made available by the National Institute of Arthritis and Metabolic Diseases, N.I.H. Prostaglandins were received from the Upjohn Company, Kalamazoo, Michigan, through the courtesy of Dr J. E. Pike. Cyanoketone was a gift of Dr G. O. Potts of the Sterling-Winthrop Research Institute. We are grateful to Mrs A. Tsafriri and Mrs Y. Osher for skilful technical assistance, and to Mr S. Yosef for devoted animal care, and to Professor P. F. Kraicer for the interest taken in this study. The contributions of two of the authors (A.T. and S.A.L.) constitute part of the requirements for the Ph.D. degree of the Graduate School of the Weizmann Institute of Science. The work was generously supported by the Population Council, New York, and the Ford Foundation.

\section{REFERENCES}

Ayalon, D., Tsafriri, A., Lindner, H. R., Cordova, T. \& Harell, A. (1972) Serum gonadotrophin levels in pro-oestrous rats in relation to the resumption of meiosis by the oocytes. F. Reprod. Fert. 31,51 .

Channing, C. P. (1970) Influences of the in vivo and in vitro hormonal environment upon luteinization of granulosa cells in tissue culture. Recent Prog. Horm. Res. 26, 589.

Cross, P. C. \& Brinster, R. L. (1970) In vitro development of mouse oocytes. Biol. Reprod. 3, 298.

EDWARDs, R. G. (1965) Maturation in vitro of human ovarian oocytes. Lancet, ii, 926.

EDWARds, R. G., Bavister, B. D. \& Steptoe, P. C. (1969) Early stages of fertilization in vitro of human oocytes matured in vitro. Nature, Lond. 221, 632.

EVERETT, J. W. (1961) The mammalian female reproductive cycle and its controlling mechanisms. In: Sex and Internal Secretions, 3rd edn., Vol. 1, p. 497. Ed. W. G. Young. Williams \& Wilkins, Baltimore.

Foote, W. D. \& Thibault, C. (1969) Recherches expérimentales sur la maturation in vitro des oocytes de truie et de veau. Annls Biol. anim. Biochim. Biophys. 9, 329. 
GIII, G. N. \& Garren, L. D. (1971) Rôle of the receptor in the mechanism of action of adenosine 3',5'-cyclic monophosphate. Proc. natn. Acad. Sci. U.S.A. 68, 786.

Grlman, A. G. (1970) A protein binding assay for adenosine $3^{\prime}, 5^{\prime}$-cyclic monophosphate. Proc. natn. Acad. Sci. U.S.A. 67, 305.

Harrington, F. E., Bex, F. J., Elton, R. L. \& Roach, J. B. (1970) The ovulatory effects of follicle stimulating hormone treated with chymotrypsin in chlorpromazine blocked rats. Acta endocr., Copenh. 65, 222.

KANATANI, H. (1969) Induction of spawning and oocyte maturation by L-methyl-adenine in starfishes. Expl Cell Res. 57, 333.

KANeKo, T., ZoR, U. \& Field, J. B. (1970) Stimulation of thyroid adenyl cyclase activity and cyclic 3',5'-monophosphate by long-acting thyroid stimulator. Metabolism, 19, 430.

Kueml, F. A., Humes, J. L., Tarnoff, J. \& Ham, E. A. (1970) Prostaglandin receptor site: evidence for an essential role in the action of LH. Science, N.X. 169, 883.

Lamprecht, S. A., Zor, U., Tsafriri, A. \& Lindner, H. R. (1971) Action of prostaglandin E $_{2}$ and LH on cyclic adenosine $3^{\prime}, 5^{\prime}$-monophosphate production and protein kinase activity in fetal, early postnatal and adult rat ovaries. Israel f. med. Sci. 7, 704.

LIPNER, M. \& GREEP, R. O. (1971) Inhibition of steroidogenesis at various sites in the biosynthetic pathway in relation to induced ovulation. Endocrinology, 88, 602.

Marsh, J. M. (1970) The stimulatory effect of prostaglandin $E_{2}$ on adenyl cyclase in the bovine corpus luteum. FEBS Letters, 7, 283.

Marsh, J. M. (1971) The effect of prostaglandins on the adenyl cyclase of the bovine corpus luteum. Ann. N.Y. Acad. Sci. 180, 416.

Mryamoto, E., Kuo, J. F. \& Greengard, P. (1969) Cyclic nucleotide-dependent protein kinases. III. Purification and properties of adenosine $3^{\prime}, 5^{\prime}$-monophosphate-dependent protein kinase from bovine brain. 7. biol. Chem. 244, 6395.

Pincus, G. \& Enzmann, E. V. (1935) The comparative behaviour of mammalian eggs in vivo and in vitro. F. exp. Med. 62, 665.

Remmann, E. M., Brostrom, C. O., Corbin, J. D., King, G. A. \& Krebs, E. G. (1971) Separation of regulatory and catalytic subunits of the cyclic $3^{\prime}, 5^{\prime}$-adenosine monophosphate-dependent protein kinase(s) of rabbit skeletal muscle. Biochem. biophys. Res. Commun. 42, 187.

Robertson, J. E. \& BAKER, R. D. (1969) Role of female sex steroids as possible regulators of oocyte maturation. Abstract, Soc. Study Reprod., 2nd Annual Meeting, Univ. Calif. Davis. Academic Press, New York.

Robison, G. A., Butcher, R. W. \& Sutherland, E. W. (1968) Cyclic AMP. A. Rev. Biochem. 37, 149.

Ronded., P. (1970) Follicular processes in ovulation. Fedn Proc. Fedn Am. Socs exp. Biol. 29, 1875.

SAVARD, K., Marsh, J. M. \& Rice, B. F. (1965) Gonadotrophins and ovarian steroidogenesis. Recent Prog. Horm. Res. 21, 285.

Schuetz, A. W. (1969) Oogenesis: processes and their regulation. In: Advances in Reproductive Physiology, Vol. 4, p. 99. Ed. A. McLaren. Academic Press, New York.

Smith, L. D. \& EcKER, R. E. (1970) Regulatory processes in the maturation and early cleavage of amphibian eggs. In: Current Topics in Developmental Biology, Vol. 5, p. 1. Eds. A. A. Moscona and A. Monroy. Academic Press, New York.

TARKowski, A. K. (1966) An air-drying method for chromosome preparations from mouse eggs. Cytogenetics, 5, 394.

TSAFriri, A. \& KRAICER, P. F. (1972) The time sequence of ovum maturation in the rat. F. Reprod. Fert. 29, 387.

Zor, U., Lamprecht, S. A., Kaneko, T., Schneider, H. P. G., McCann, S. M., Field, J. B., Tsafriri, A. \& Lindner, H. R. (1972) Functional relations between cyclic adenosine 3',5'-monophosphate, prostaglandins and luteinizing hormone in rat pituitary and ovary. Proc. Int. Conf. Physiology and Pharmacology of Cyclic AMP, Milan, 197I. In: Advances in Cyclic Nucleotide Research. Eds. P. Greengard, G. A. Robinson and R. Paolotti, Raven Press, New York. (In press). 